\title{
ABOUT THE ECONOMIC FACTORS OF THE PROCESS OF FERTILITY IN CONTEMPORARY RUSSIA
}

\author{
Senior lecturerIgor Malimonov ${ }^{1}$, \\ Assos. Prof. Irina Sinkovskaja ${ }^{1}$, \\ Assos. Prof. Dmitriy Rakhinskiy ${ }^{1}$, \\ Assos. Prof. Ludmila Korol ${ }^{2}$ \\ Senior lecturer Julia Shepeleva ${ }^{1}$ \\ ${ }^{1}$ Siberian Federal University, Russia \\ ${ }^{2}$ Siberian state university of science and technology, Russia
}

\begin{abstract}
The article deals with the process of childbirth and the factors affecting it. Actuality of this work is caused by the significant decline in the birth rate in Russia in 2017-2018. The article describes the institution of the family as an integral part of the socio-economic structure of society, in which changes of the whole system naturally entail changes in its elements. Groups of factors influencing the childbirth process are determined. The main attention is devoted to the analysis of the influence of economic factors that form the demographic situation in modern society. The article identifies and analyzes the main economic factors affecting the birth rate. The influence of different economic conditions of family life on reproductive attitudes is described. The article deals with the actual problems of childbirth in the conditions of socio-economic reform of the Russian society. The presented theoretical calculations are confirmed by the data of various empirical studies. The materials of the article are of theoretical and practical value for employees in the field of social research in sociology, philosophy, psychology.
\end{abstract}

Keywords: childbirth, demographic transition, reproductive behavior, economic factors of childbirth, transformation of family relations.

\section{INTRODUCTION}

Birth rate is an important demographic process which determines the reproduction type of the population, the labor potential of the country. The depopulation processes observed in Russia today acquire a long-term character and will have a negative impact on the socio-demographic situation, that is why understanding causes of fluctuations in the birth rate, their nature, subjective (change in common family values, reducing personal need to have children) or objective (presence of barriers that do not give people the opportunity to fully realize their reproductive attitudes), is important for the formation of an adequate demographic policy in Russia. In this regard, the study of childbirth 
factors, their importance for a modern Russian family and the possible impact on reproductive plans is an urgent topic.

Throughout the presented work the solution of the following tasks is proposed: 1) to consider the theoretical aspects of childbirth; 2) to analyze the economic factors affecting the demographic process of childbirth.

Science uses now the concept of natural or hypothetical birth rate proposed in 1961 by French demographer L. Anri:" Natural birth rate is birth rate, level of which is due only to physiological and structural factors, i.e. the state of childbirth and the structure of the population by sex, age and marital status in complete absence of deliberate birth control using contraceptives and abortions " [3, p.109].

But natural fertility is limited by a number of factors arising in the process of socio-economic development of society, that eventually formed the historical type of childbirth, which can be defined as a set of the most significant qualitative features of childbirth, which are the basis of the process of successive replacement of generations during the reproduction of the population in a relatively similar historical, social, economic and other conditions. The change of the historical type of childbirth is characterized by the revision of the norms of reproductive and matrimonial behavior, the change in the optimal number of children in the family and determination of the birth rate.

Depending on the socio-economic conditions of the society existence, four historical types of childbirth can be distinguished: prehistoric, antique-feudal, demographic transition and modern. The latter type is characterized by feminism and women's emancipation development, which arose in the process of transformation of socio-economic relations, as a result changed the traditional gender roles in society and the family and manifested in the development of non-family employment of women having economic and family independence, which affected their reproductive settings. In addition, the elimination of child employment and the increase in material costs for child care made the high birth rate economically unprofitable.

The birth rate is influenced by many factors (socio-economic, demographic, and psychological) but admitting the importance of all groups of factors, we believe that economic factors are the basis for changing reproductive attitudes of the population.

The opinion on the impact of economic factors on reproductive settings was different, but constant. So in the XVII century E. Halley claimed that"... growth and increase of mankind is not so much constrained by something lying in the nature of man, as due to the caution shown by the majority of 
the population at the decision to marry on the basis of the prospects to have concerns and burden for providing the family" [7, p.102-103].

The influence of economic factors explains the origin of such form of family-marriage relations as monogamy. According to F. Engels the basis of the formation of monogamy is the victory of private property over public. Since private property was concentrated primarily in men the monogamous family was "the domination of the husband with the defined purpose of the birth of children, the origin of which from a certain father is in no doubt and this indisputability of origin is necessary because children over time as direct heirs should take possession of the father's property" [11, p.65].

The problem of marriage stability and factors influencing it is actively studied in modern foreign studies. Hence the importance of socio-economic factors for marriage stability was noted by American sociologists Lewis and Spanner. These factors included: "material well-being (stability of income, wife satisfaction with extrafamilial professional activities), family structure, family planning, family inclusion into social circles of communication" [13, p. 242].

Also, from the standpoint of the economic approach, the stability of family institution and marriage by G. Becker is analyzed, who highlights the principle of maximizing utility, the key concept of which is "family capital". As the author notes "market employment and growth of relative women's earnings increase their market human capital, reduce dependence on family capital, increase benefits associated with divorce that consequently makes marriage more unstable" [2, p. 426]. In addition, Becker's works on economic theory of childbirth indicate that " the impact of women's employment on childbearing should be negative (because the opportunity costs of having children for employed women are higher), while the impact of men's employment is positive (men's employment increases family resources)" [12, p. 498].

The influence of economic factors on family functioning is also reflected in the theories of exchange (J. Homans, P. Blau, etc.). According to them family is a socio-economic phenomenon, which is based on the process of exchange of values, both material (money, household items) and intangible (love, respect, recognition). Based on this understanding of the family the costs of having children should be at least reimbursed.

The importance of economic factors is emphasized in the national science. So the importance of economic factors is noted in the works of V.N. Arhangelskiy: "in modern conditions mainstreaming of factors such as economic behavior of the family, family property, inheritance (including business) is possible in terms of the impact on reproductive behavior. So we can assume that these factors affect the conditions of the existing demand for children, as well as the value orientation" [1, p. 37]. 
Based on the analysis of foreign and domestic authors' works the following economic factors affecting the birth rate can be identified:

1. Family income.

2. Housing facilities.

3. Economic benefits of having a child in the family.

4. Professional status in the labor market.

5. Women's employment rate.

One of the most important economic factors affecting the birth rate is the family income. Income is the amount of money and natural income (in monetary terms) received by all family members who have an independent source of livelihood. Current financial situation of the family, first of all, consists of the income of the husband and wife. Lack of wife's earnings during pregnancy, maternity leave and child care, her forced presence at home due to lack of place in the children's preschool can significantly complicate family financial situation. Women's working conditions are also important for the family budget. For example, maternity leave, child care may be associated with the loss of position or qualification.

At present, for modern Russian society one of the highest values has become a success, expressed primarily in material prosperity, career and social calling. At the same time, mostly having low level of income, the population tries to ensure minimum standards of living, so that the choice is not in favor of the childbirth, but in favor of meeting other more "profitable" needs (career growth, material success and desired pastime). The family seeks to do everything possible to provide material support, limiting the number of children born, which allows you to get a certain material and economic condition, protecting oneself from stressful situations.

In support of the above, we can cite the data of monitoring the socio-economic situation of families, conducted under the auspices of the Ministry of social protection of the Republic of Tatarstan. Analysis of the information received showed that respondents with two children were more dissatisfied with the economic standard of living in the family than respondents with one child. The difference in answers allows L. Cartseva to say that "...it is well to have children, and to have nonein modern conditions-even better", because...there are not so much problems in life, as a feeling of fear and uncertainty that the new children will receive proper education and upbringing" [4, p. 96]. So the transition to childlessness is a pronounced adaptive strategy in modern society that can be changed primarily by "carrying out an active demographic policy based primarily on improving the financial situation of the population" [5, p. 270]. 
The following significant economic determinant of reproductive behavior are housing conditions: size of living space for one family member, options for layout (apartments of a small area, with communicating rooms, with combined bathrooms), amenities (garbage disposal, lift, etc.), availability of repair, distance to place of work. Currently, the housing conditions of a significant part of Russian families are still unsatisfactory, and the change is hampered by insufficient income. The same point of view adheres L. Kartseva, considering that "the lack of normal living conditions has put Russian people in front of the necessity of limiting the number of children" [4, p. 97].

Also, a group of economic factors include the economic benefits of having children in the family. If the availability of children is related to income equal to or greater than income from other activities, the birth rate is set at the highest possible level, which is limited only by the level of child mortality and the spread of infertility. Thus, in pre-revolutionary Russia working children were the main source of income in peasant families and breadwinners in old age, which determined the high economic need for children and kept the birth rate at the level of 7-8 children per family.

In our opinion, in Russia the economic benefit of having children in the family is represented by:

1) state material support of maternity (state one-time benefits, maternity (federal and regional capital), paid leave for child care up to 1.5 years, social benefits);

2) parents ' expected help in old age, when it is difficult to provide oneself and serve

But these components are currently not relevant for all families. Thus, the beginning of independent professional activity of the younger generation is moving to the age of 20-25 years, thereby increasing the period of maintenance and costs. And the presence of the pension system in Russia also makes elderly parents less independent from children's help.

Another important economic factor determining the number of children in the family is the professional status of parents (especially mothers). Modern society creates a dilemma of production of material values and the birth of children (child production). The higher the income of parents, the more profitable is to work and less time left for children. In addition, the participation of women in industrial relations directs them to the most popular type of successful, business-like, independent woman in industrial society. As a result, there is a contradiction between the role of the mother and the professional, which ultimately manifests itself in the negative impact of the labor status of women on the birth rate (postponing the birth of the first or even the only child at a later date). In practice, however, holds the view that unemployed women without labor income also postpone having children or reject it, because they rate themselves frustrated in the material sense [14, $\mathrm{p}$. 312]. 
Therefore, the impact of such factors as the professional status and level of employment of parents on the birth rate is ambivalent - they can both contribute to the increase in childbirth and cause its decline. This is confirmed by the results of sociological research "Education and employment", conducted by the Independent Institute of social policy with the support of the scientific society of M. Planck (Germany, 2005) in 32 regions of Russia $(\mathrm{N}=6455)$. The study revealed that among the women who gave birth, there were more women who had a job a year before the birth of a child (70\% against $30 \%$ of the unemployed). However, the proportion of women with jobs among the non - mothers is also very high, at 74 per cent. [6, p. 78].

Having considered the selected economic factors, it should be noted their increase of impact during crisis periods, causing a drop in the usual standard of living of the family and, first of all, the families of the poor. In such periods the birth rate is usually reduced. A striking example of such changes is Russia 90-ies of XX century, when the management system was aimed at the neoliberal course, which negatively related to the state forms of social support and recommended to minimize the state's influence in the social sphere. In situations of economic downturn, childbirth decline is one of the ways to solve economic problems - the cost of child support is minimized. A typical picture of the family budget with economic uncertainty is well characterized by G. M. Rossinskaya:" Budgets of most households have become essentially survival budgets, so that many functions of families (including reproductive) were in a depressed state, having lost the material basis of its implementation, degraded "[9].

With this view coincides the opinion of V. K. Stankunene: "In periods of economic crisis the number of marriages and births tends to decrease. In addition, in times of economic instability, people avoid additional responsibilities and obligations, at least permanent and long-term. This is the minimization of possible additional costs for children, their education, etc." [10, p. 59]. As a result, the birth of a child is postponed to a later date. And in such situation, a very important question arises: "Is the state able, using various available strategies, including innovative ones, to solve both existing and constantly emerging new social and psychological problems of the modern family?"[8, p. 322].

\section{CONCLUSION}

Summing up the analysis of the impact of economic factors on the demographic process of childbirth, the following should be emphasized: 
1. The birth rate in Russia is directly related to the impact of such economic factors as: population income, family housing conditions, professional status of parents, the level of employment of women, economic benefits from children.

2. Economic factors are an objective reason that forms a psychological barrier, which in a situation of unfavorable economic situation does not allow families to realize their reproductive attitudes.

3. In the case of prolonged economic crises, the reduction of reproductive plans can become a trend that lays a new social standard of small families.

4. In the development of demographic and social policy, it is necessary to take into account the leading role of economic factors and carefully build partnerships between the state and the family (flexible forms of employment of women during child care, the development of the market of social services for the care and upbringing of children, preferential mortgage programs for large families).

5. The ambivalence of a number of economic factors (family income, professional status of parents) indicates that in the development of programs to stimulate the growth of childbirth it is necessary to consider them in combination with non-economic factors (transformation of family relations, improving the level of education, attitudes and values, religious traditions, etc.), affecting the birth rate and sometimes unrelated to the growth of material well-being of the population.

\section{REFERENCES}

[1] Arhangelskiy V.N. System of indicators for the analysis of the demographic situation / Family in Russia, Russia, 1997. №. 2. pp. 36-52;

[2] Becker G. Human behavior: an economic approach. M.: GU VSHE, P. 671, 2003.

[3] Borisov V.A. Demography. M.: NOTABENE, P. 272, 2001.

[4] Kartseva L.V. Family model in the conditions of transformation of the Russian society / Sociological researches, Russia, 2003. №. 7. pp. 92-100;

[5] Korol L.G., Malimonov I.V., Rakhinskiy D.V., Sinkovskaja I.G. Dynamics of the sociodemographic situation in Krasnoyarsk region / Kazan science, Russia, 2014. №. 11. pp. 268-270;

[6] Maleva T.M., Sinyavskaya O.V. Socio-economic factors of fertility in Russia: empirical measurements and challenges of social policy / Social policy: expertise, recommendations, reviews, Russia, 2006. №. 5. pp. 70-97;

[7] Ptukha M.V. Essays on the history of statistics XVII-XVIII centuries. M.: Ogiz Gospolitizdat,. P. 352, 1945.

[8] Sochneva E.N. Social entrepreneurship: place and role in the regional economy of innovative development // Fundamental research, Russia, 2016. №. 9-2. pp. 321-324; 
[9] Rossinskaya G.M., Skryabina Y.A. influence of socio-economic features of the transformational Russian economy on the reproductive behavior of the population and fertility [Electronic resource]. URL: http://www.demographia.ru/articles_N/index.html?idR=20\&idArt=1962 (date of circulation: 17.12.2012).

[10] Stankuniene V.K. A turn for the modern family model in Lithuania: characteristics, factors, installation / Sociological research, Russia, 2004. №. 5. pp. 54-65;

[11] Engels F. Origin of family, private property and state / Marx K., Engels F. Compositions. Is. 2: State publishing house of political literature, 1961. Vol. 21. pp. 28-178;

[12] Becker G. A Theory of Allocation of Time // Economic Journal, United Kingdom, 1965. Vol. 75. pp. 493-517;

[13] Lewis R., Spanier G. The Rising about the Quality and Stability of Marriage / Contemporary Theories about the Family. Vol. 2 / eds. W. Burr a. o. N. Y., 1979. Pp. 239-248;

[14] Meron M., Widmer I. Unemployment Leads Women to Postpone the Birth of Their First Child / Population. English Edition, France, 2002. Vol. 57. № 2. pp. 301-330;

[15] Kudashov V.I., Chernykh S.I., Yatsenko M.P., Grigoreva L.I., Pfanenshtil I.A., Rakhinskiy D.V. Historical reflection in the educational process: an axiological approach / Analele Universitatii din Craiova - Seria Istorie. 2017. Vol. 22. № 1. pp. 139-147;

[16] Baksheev A.I., Nozdrin D.A., Turchina Zh.E., Sharova O.Ya., Yurchuk G.V., Rakhinskiy D.V. Bioethical principles and mechanisms for regulation of biomedical research / Journal of Pharmaceutical Sciences and Research. 2018. Vol. 10. № 4. pp. 889-892; 